\title{
Herbal Flavoured Milk and Sensory Evaluation
}

\author{
Mogla Achal Maharaj Kishore, D.K. Chaturvedi* and P.K. Dantu \\ Dayalbagh Educational Institute (Deemed to be Univ.), Dayalbagh, Agra, U.P., India \\ *Corresponding author
}

\begin{abstract}
A B S T R A C T
Keywords

Herbal Flavoured milk, Tulsi flavour, Lemongrass flavour, Fennel flavour, Taste

\section{Article Info}

Accepted:

15 April 2020

Available Online:

10 May 2020

This study deals with the consumer sensory evaluation of herbal flavoured milk prepared with the help of herbs having medicinal properties. Three herbs that have been chosen are Fennel, Tulsi and Lemongrass Oil. This herbal flavored milk is prepared for with different compositions of these flavours and the effect is studied. The correlation has been established between different age group, gender and weight with their liking (sensory evaluation).
\end{abstract}

\section{Introduction}

The flavoured milk is mostly liked by the people of all age group, gender, height and weight. In the past studies, there is no correlation available between these parameters and the composition of flavoured milk. In this paper, a survey method is used to study the effect of different level of composition of flavoured milk and its liking by different age, gender, height and weight people. The correlation is established between these parameters and level of composition of flavoured milk. For this purpose three different flavours have been selected namely, Tulsi, Fennel and Lemon grass because of their medicinal values.
Tulsi was chosen because it lowers the risk of heart, disease, soothes fever, headache and sore throat. Fennel was chosen because it helps in the purification of blood, improves eyesight, helps in lowering of blood pressure and reduces fiber. Lemongrass oil was the third herb chosen because of the benefits that it offers like having anti-bacterial properties, anti- oxidant properties and also prevention of gastric ulcers. Herbal flavoured milk was prepared using the above 3 herbs using different compositional details of which are as under:

Tulsi was added in 4 different compositions in flavoured milk which is consisting of $5 \mathrm{gm} / \mathrm{ltr}$, $10 \mathrm{gm} / \mathrm{ltr}, 15 \mathrm{gm} / \mathrm{ltr}$ and $20 \mathrm{gm} / \mathrm{ltr}$. of Tulsi 
powder per litre of milk. The reason why 15 gm was chosen as the maximum was that upon adding $20 \mathrm{gm} / \mathrm{ltr}$ - it was found that the milk got spoilt.

Fennel was added in 3 different compositions of $5 \mathrm{gm}, 10 \mathrm{gm}$ and $15 \mathrm{gm}$ fennel powder per litre of milk. The reason why $15 \mathrm{gm}$ was chosen as the maximum was that upon adding $20 \mathrm{gm}$ - it was found that the milk got spoilt.

Lemongrass oil was added in 4 different compositions of $1 \mathrm{ml}, 5 \mathrm{ml}, 7 \mathrm{ml}$ and $10 \mathrm{ml}$ per litre of milk. It was found that the samples having $7 \mathrm{ml}$ and $10 \mathrm{ml}$ compositions were bitter in taste and not at all acceptable by the audience.

The consumers of all age groups have been included in this study and a consumer survey was done of the 3 different samples of herbal flavoured milk of different compositions on the organoleptic characteristics. Sensory evaluation was done because it has been found that evaluation of the sensory characteristics of food products is said to be the best possible method for evaluation of product quality (Schiano et al., 2017). Results obtained from the survey were compared with respect to 3 different parameters: Age, Weight and Gender.

Milk is said to be a complete food in itself having all the necessary minerals, vitamins and proteins needed for the complete development of an individual. It has been mentioned as the wonder drink having magical health benefits since centuries. Milk inspite of being a complete food in itself a new category of drinks having been developed known by the name Nutraceuticals. Nutraceuticals are functional foods and dairy products occupy a significant space in the functional foods market and dairy based functional foods are the latest addition to this segment. The reason for Nutraceuticals finding a place is that people have become more aware about their health and the belief that intake of healthy food is more important than simply increasing the no of years in the life of a person (Ozer et al., 2010).

In this paper herbal flavoured milk has been prepared with 3 different herbs / their extracts and the sensory evaluation has been done and its effect on the consumer perception with respect to age, weight and gender was analyzed. The herbs were added into cow milk on the basis of sensory evaluation (different concentrations) using 9 point hedonic scale. Herbs have been chosen because of their medicinal properties and it has been found that medicinal positive traits of herbs can be effectively carried by certain foods as carriers. Milk is one of the most important carriers which have been effectively used to deliver phytochemicals present in traditional herbs (mainly polyphenols) for specific health benefits in the traditional Indian system of medical science (Sawale Digamber et al., 2015).

Technically flavoured milk is a product that contains raw milk in which whole nuts (fragmented or grounded), Elaichi (cardamom), Badam (almonds), chocolate, cocoa powder, coffee or another edible food colour or flavours and cane sugar have been added.

\section{Relation between milk and Ayurvedic herbs}

Since Vedic times health benefits of milk have been enhanced through use of herbal infusions. This co-relation is used for prevention against a list of diseases and to overcome nutritional deficiencies. Nutritional deficiency is almost impossible to avoid in these modern times, thus natural supplements help in overall growth, development and enhanced immunity. Herbs are also useful in getting rid of toxins accumulating in the body. India as a country is rich in different herbs 
that have been used for various medicinal purposes (Mazid et al., 2012).

Ayurvedic system has the oldest and one of the most developed herbal systems in the world - it has been in continuous use for at least 5,000 years. The ancient Vedic seers in India compiled and classified medicinal and healing properties of hundreds of herbs into an herbal healing system that can be accessed and utilized by anyone.

One of the latest things is the production of new flavoured milk products using herbs. Given below is the list of ayurvedic herbs that can be added to milk to make flavoured Milk:

Brahmi, Tulsi , (Kumar et al., 2013), Ginger (Palthur et al., 2014), Shatvari (Veena et al., 2015), Turmeric, Alfafa, Stevia, Khajoor, Aloe Vera, Cumin, Coriander, Cinnamon, Black pepper, Mace, Bay leaf, Poppy seeds, Liquorice or Mulethi, Jatamansi or Spikenard and Pueraria tubersosa (Sawale et al., 2015). Recently a new product by the name of memory milk has been developed by a major brand in the market under the category of sterilized homogenized flavoured toned milk that contains combination of various ayurvedic herbs like Brahmi, Shankpushpi, Tulsi, Ashwagandha and other herbs.(www.amul.com/products/AmulMemoryMilk)

As mentioned above also, in the previous studies done on herbal flavoured milk it was found that ginger was of the preferred herbs to be added to cow milk and its effect was studied in terms of the quality, texture characteristics, and sensory evaluates of the final product (Palthur et al., 2014). Sensory evaluations have also been done and the customer responses to salt, fat and unfamiliar foods have been tested in both the young and the old (Tuorila, 2015).

\section{Materials and Methods}

\section{Design/methodology/approach}

We can use various herbs like cumin, coriander, cinnamon, black pepper, nutmeg, bay leaf, liquorice or Mulethi, jatamansi with raw milk to produce herbal flavored Milk (Chourasia, 2011). We can try to develop a new herbal flavoured milk product using either two or three herbs (e.g. Ashwagandha, Spirulina, Shatavari, Tulsi, Fennel, etc.) that have medicinal value and also using different substitutes of sugar for sweetening.

Herbs were selected depending on their medicinal properties and other benefits that it provides to the human body. Three different herbs were chosen namely Lemongrass, Tulsi and Fennel. Lemongrass was chosen because it has various anti - bacterial properties and it is effective against drug resistant bacteria that are responsible for causing skin infection, blood infection and intestine infection. It is having an anti-fungal property and it helps in easing diarrohea. It is also known to have an anti- inflammatory property because of presence of citral. The leaves and the whole plant of the lemon grass are generally used for extraction (Shah et al., 2013).

The $2^{\text {nd }}$ herb chosen was Tulsi. It is also known as the Holy Basil or Elixir of Life or Incomparable one. The Botanical name of Tulsi is Ocimium sanctum L. / Ocimium tenciflosum $\mathrm{L}$. There are 3 main types of Tulsi Plant: 1) Rama or Green leaf Tulsi. 2) Krishna Tulsi or Shyama or Purple leaf Tulsi and 3) Vana Tulsi or Wild leaf Tulsi. We have used Tulsi because it is known to possess medicinal properties like analgesic activity, anti-ulcer activity, anti-arthritic activity, antiasthmatic, anti- cancerous, anti- diabetic, antiinflammatory, anti- oxidant, antiinflammatory, anti- oxidant and anti - stress activity (Kadian and Parle, 2012). 
$3^{\text {rd }}$ herb chosen was Foeniculum vulgare. It is a perennial aromatic plant which belongs to the Apiceae family. It initially was grown in the Mediterranean region but now is cultivated throughout the world and is known commonly as Fennel. It has been chosen because it is known to have medicinal properties like being an anti-oxidant, antiinflammatory, diuretic in nature. It also has properties like anti-microbial, antihypertensive, gastroprotective and antithrombotic properties (Fennal Akbar, 2018).

Samples of herbal flavoured milk were prepared depending on the concentrations given below:

\section{Lemongrass oil}

Lemongrass oil after extraction was added to milk in 4 different concentrations $10 \mu \mathrm{L}, 50$ $\mu \mathrm{L}, 70 \mu \mathrm{L}$ and $100 \mu \mathrm{L}$ per litre. The fat $\%$ in milk was kept as $1.5 \%$ and the sugar concentration was kept maximum $3.0 \%$ for adults. It was found that the samples having $70 \mu \mathrm{L}$ and $100 \mu \mathrm{L}$ per litre concentrations were bitter in taste and not at all acceptable by the audience.

\section{Tulsi}

Herbal flavoured milk samples were prepared where Tulsi was added in 3 different concentrations $5 \mathrm{gm}, 10 \mathrm{gm}$ and $15 \mathrm{gm}$ per litre. The fat $\%$ in milk was kept as $1.5 \%$ and the sugar concentration was kept maximum $3.0 \%$ for adults. The reason why $15 \mathrm{~g}$ was chosen as the maximum was that upon adding $20 \mathrm{~g}-$ it was found that the milk got spoilt.

\section{Fennel}

Herbal flavoured milk samples were prepared where Fennel was added in 3 different concentrations $5 \mathrm{gm}, 10 \mathrm{gm}$ and $15 \mathrm{gm}$ per litre. The fat $\%$ in milk was kept as $1.5 \%$ and the sugar concentration was kept maximum $3.0 \%$ for adults. The reason why $15 \mathrm{gm}$ was chosen as the maximum was that upon adding $20 \mathrm{gm} / \mathrm{lt}$ - it was found that the milk got spoilt.

Once these three samples were made an organo leptic analysis was done by the general public through a survey and the samples were graded on a 5 point hedonic scale. The analysis was done keeping in mind the 3 different parameters: Gender, Age and Weight.

\section{Results and Discussion}

\section{Gender}

\section{Lemongrass}

The $70 \mu \mathrm{L}$ and $100 \mu \mathrm{L}$ concentration samples were found to be bitter in taste and were unacceptable. Therefore the optimum acceptable concentration that was fixed for lemongrass oil content was $10 \mu \mathrm{L}$ and $50 \mu \mathrm{L}$.

As seen from Figure 1 (a), it was found that in case of males liking for flavour Content in $\mu \mathrm{L} /$ litre for both the samples of $10 \mu \mathrm{L}$ and $50 \mu \mathrm{L}$ was similar.

Females also liked both the samples of $10 \mathrm{uL}$ and $50 \mu \mathrm{L}$ respectively but the liking was slightly more in case of $10 \mu \mathrm{L}$ samples (Figure 1a).

\section{Tulsi}

For 5 gm sample: As seen from Figure 2 (a), it was observed that females who liked the $5 \mathrm{gm}$ concentration samples were more in concentration / frequency than the males.

For $10 \mathrm{gm} / \mathrm{ltr}$ sample: As seen from Figure 2 (a), it was observed that the liking for flavour 
Content in gms/ litre for $10 \mathrm{gm}$ concentration sample was similar for both males and females.

For $15 \mathrm{gm} / \mathrm{ltr}$ sample: It was observed that the liking for flavour Content in gms/ litre for 15 gm/ltr concentration sample was far more in females as compared to the male counter parts. Figure 2 (a)

\section{Fennel}

For $5 \mathrm{gm} / \mathrm{ltr}$ sample: As seen from Figure 3 (a), it was observed that liking flavour Content in gms/ litre for females who liked the $5 \mathrm{~g}$ concentration samples were more than the males.

For $10 \mathrm{gm} / \mathrm{ltr}$ sample: It was observed that liking flavour Content in Gms/ litre for males who liked the $10 \mathrm{gm} / \mathrm{ltr}$ concentration samples were more than the females (Figure 3a).

For $15 \mathrm{gm} / \mathrm{ltr}$ sample: It was observed that liking flavour Content in Gms/ litre for females who liked the $15 \mathrm{gm} / \mathrm{ltr}$ concentration samples were more than the males (Figure 3a).

\section{Age}

\section{Lemongrass}

It was found that with the increase in age- in 10 micro L samples - the flavour Content in $\mu \mathrm{L} /$ litre initially increased, became stagnant and then decreased. Figure 1 (b)

In case of 50 micro $\mathrm{L}$ samples it was found that with the increase in age the flavour Content in $\mu \mathrm{L} /$ litre initially increased, then showed a very steep fall and then again increased. Figure 1 (b)

\section{Tulsi}

As seen in Figure 2 (b), for 5gm sample it was found that with the increase in age the flavour
Content in gms/litre also increased. For $10 \mathrm{gm}$ sample it was found that with the increase in age the flavour Content in gms/litre also increased up to a certain point and then gradually decreased (Figure 2b).

For 15 gm sample it was found that with the increase in age the flavour Content in gms/litre decreased (Figure 2b).

\section{Fennel}

For $5 \mathrm{gm}$ sample it was found that with the increase in age the flavour Content in gms/litre went on decreasing (Figure 3b).

For $10 \mathrm{gm}$ sample it was found that with the increase in age the flavour Content in gms/litre initially increased up to a certain point, became stagnant and then gradually decreased (Figure 3b).

For $15 \mathrm{gm}$ sample it was found that with the increase in age the flavour Content in gms/litre was stagnant initially to a certain point and then went on increasing (Figure 3b).

\section{Weight}

\section{Lemongrass}

As seen in Figure 1 (c), it was found that with the increase in weight - in $10 \mu \mathrm{L}$ samples flavour Content in $\mu \mathrm{L} /$ litre kept on decreasing then gradually became stagnant.

In case of $50 \mu \mathrm{L}$ samples it was found that with the increase in weight the flavour Content in $\mu \mathrm{L} /$ litre decreased, then it increased and in the last phase it decreased. Figure 1 (c)

\section{Tulsi}

For $5 \mathrm{gm}$ sample it was found that with the increase in weight the flavour Content in gms/litre also increased initially, then it 
became stagnant and there was no increase even with the increase in weight (Figure 2c).

For $10 \mathrm{gm}$ sample it was found that with the increase in weight the flavour Content in gms/litre decreased initially, then increased substantially, then decreased substantially and then again increased (Figure 2c).

For $15 \mathrm{gm}$ sample it was found that with the increase in weight, the flavour Content in gms/litre increased initially, then decreased, increased again and then decreased again in the last stage (Figure 2c).

\section{Fennel}

As seen in Figure 3 (c), for $5 \mathrm{gm}$ sample it was found that with the increase in weight the flavour Content in gms/litre remained constant for the weight between 45 kilograms to 70 kilograms and then as the weight increased further the flavour Content in gms/litre also increased.
For $10 \mathrm{gm}$ sample it was found that with the increase in weight. The flavour content in gms/litre remained constant for the weight between 45 kilograms to 78 kilograms and then as the weight increased further the frequency of liking also increased (Figure 3c).

For $15 \mathrm{gm}$ sample it was found that with the increase in weight, the flavour Content in gms/litre decreased initially, then increased and then gradually decreased (Figure $3 \mathrm{c}$ ).

In conclusion, females liked lower concentration in the case of lemongrass in comparison to males. In case of Fennel and Tulsi, it was found that females liked both $5 \mathrm{gm}$ and $15 \mathrm{gm} / \mathrm{ltr}$ flavour Content and 20 gms/ litre more than the males. Therefore it could be safely concluded that females have a better organoleptic evaluation capacity than males because they can easily make out the highs and the lows in any food product / beverage.

Results obtained after organoleptic survey of herbal flavoured milk (lemongrass, tulsi and fennel)

\section{LEMONGRASS}

Figure.1 (a) Gender

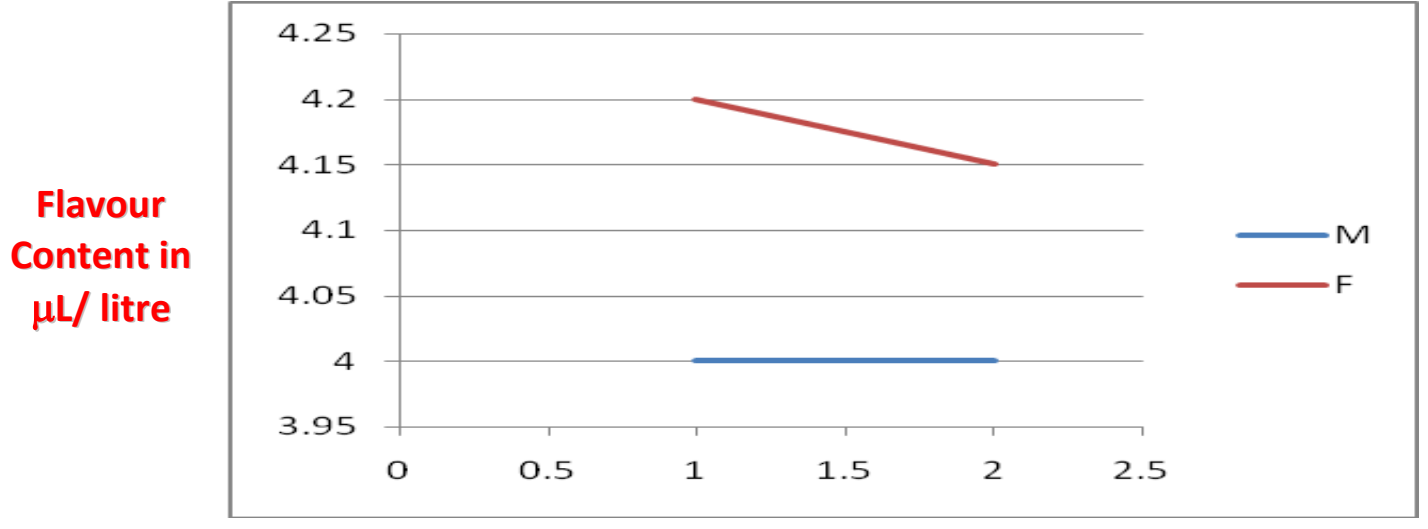

Concentration $\mu \mathrm{L} /$ litre 
Figure.1(b) Age

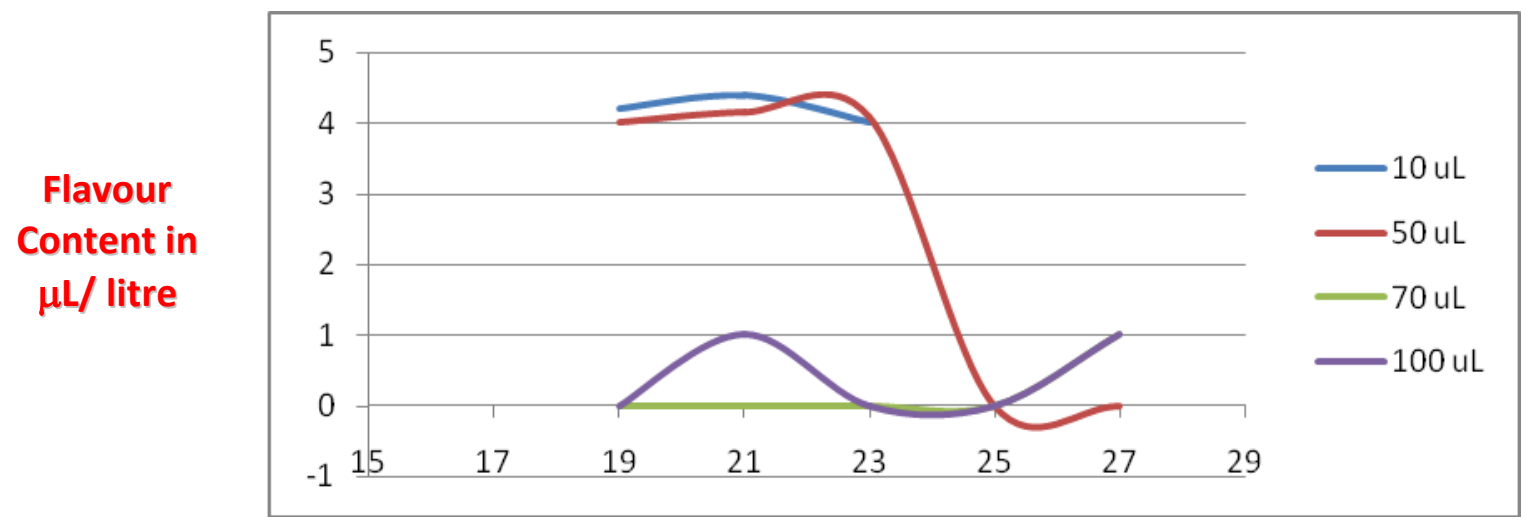

Age in years

Figure.1(c) Weight

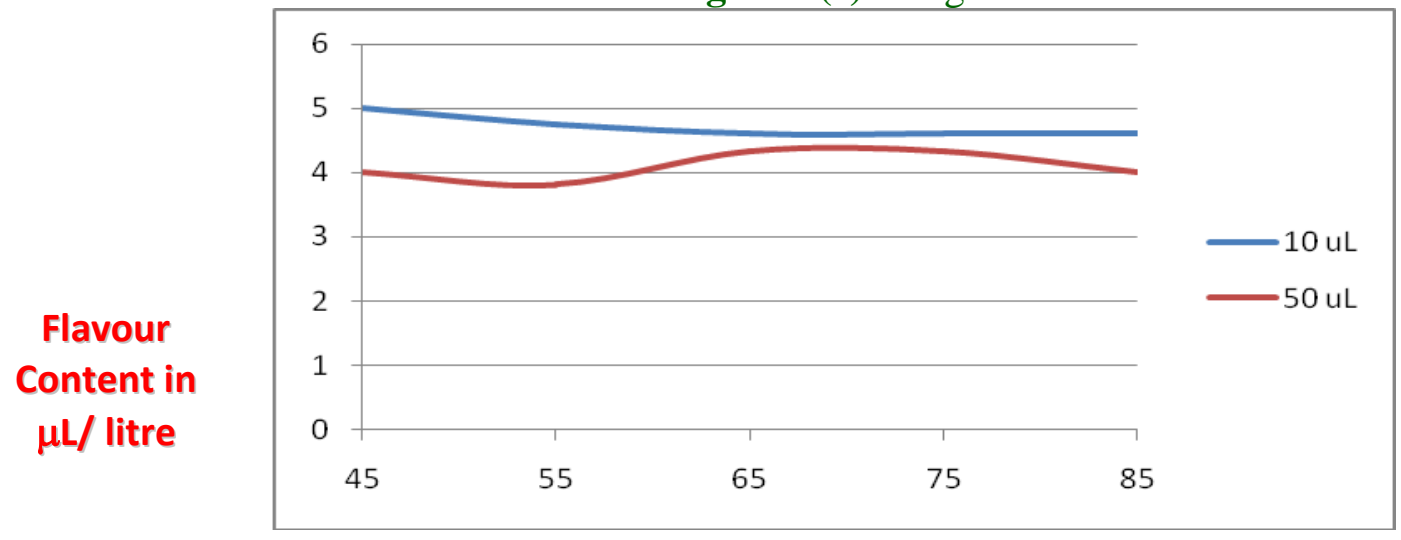

Wejght in kgs

Figure.2(a) Gender

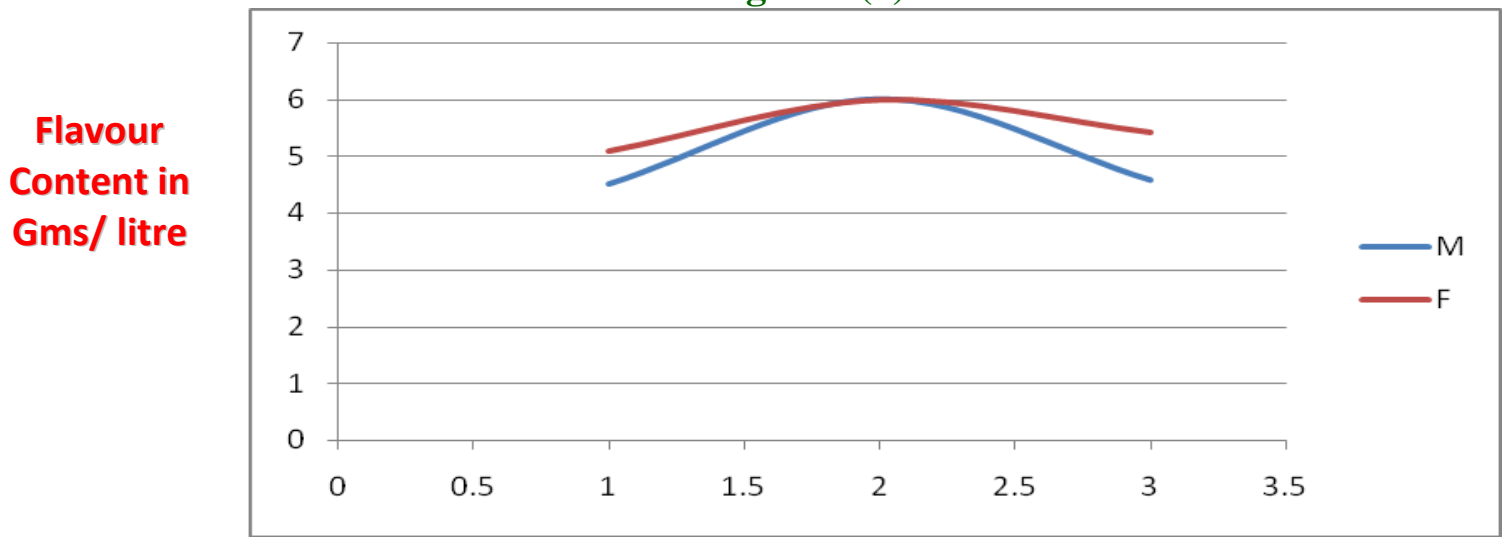

Concentration in Gms/litre 
Flavour Content in gms/litre
Figure.2(b) Age

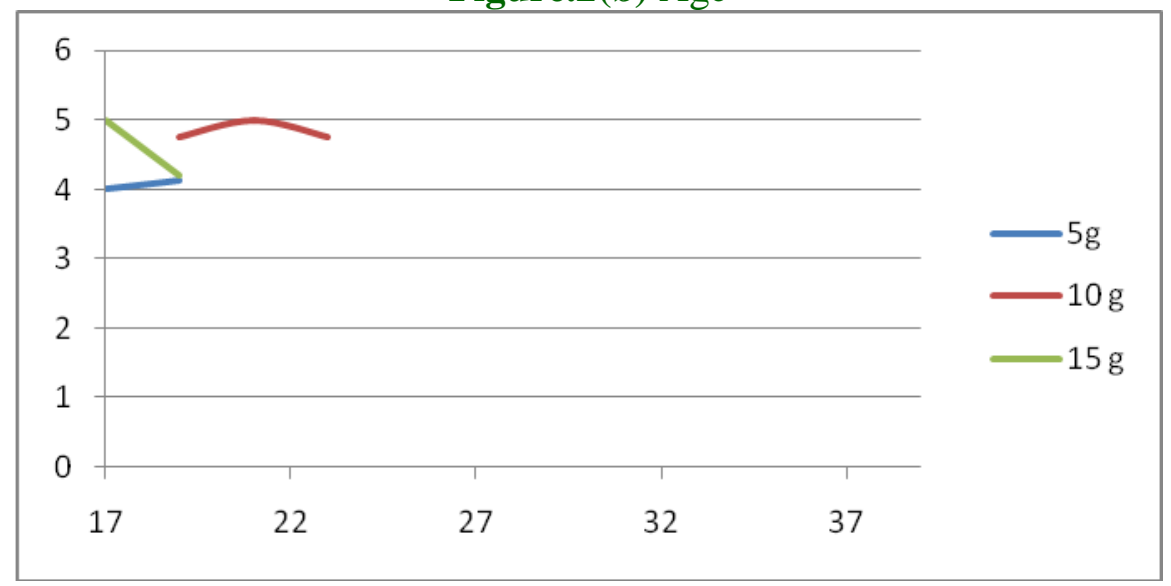

Age in years

Figure.2(c) Weight

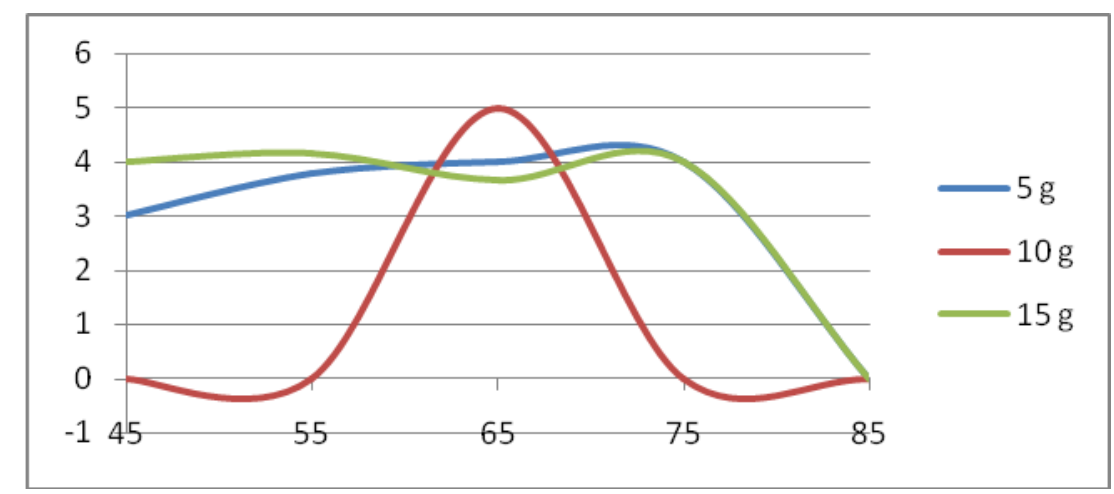

Weight in kgs

\section{FENNEL}

Figure.3(a) Gender

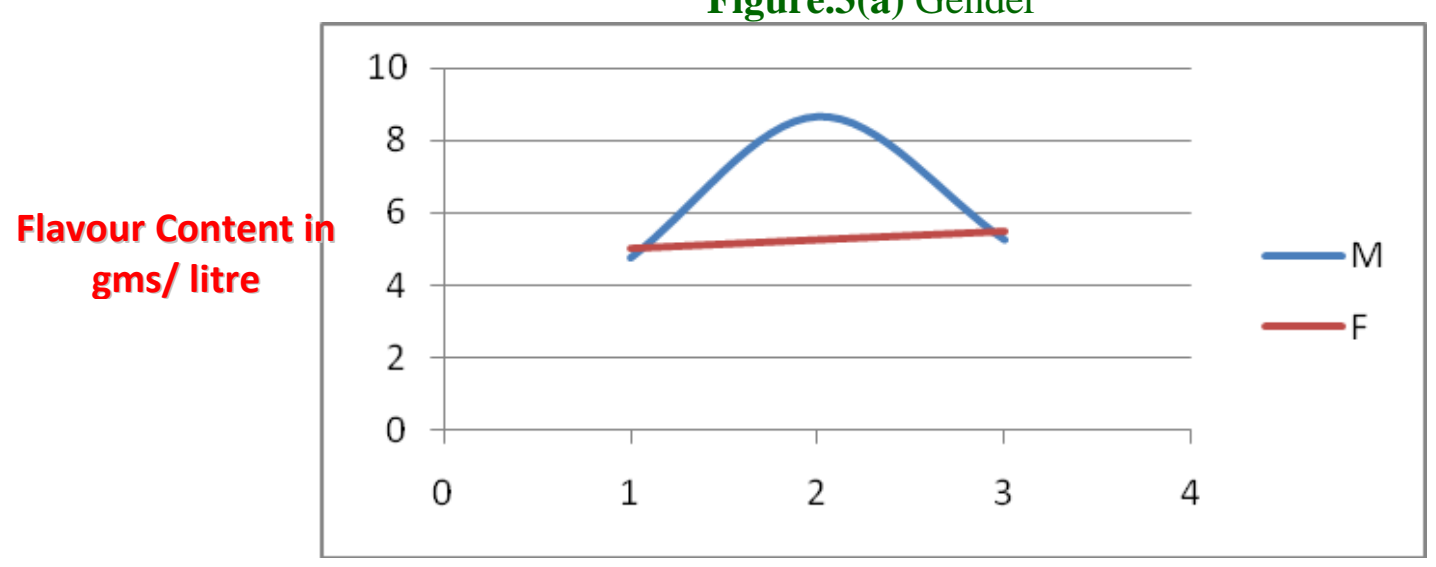

Frequency of liking 
Figure.3(b) Age

\section{Flavour Content in gms/ litre}

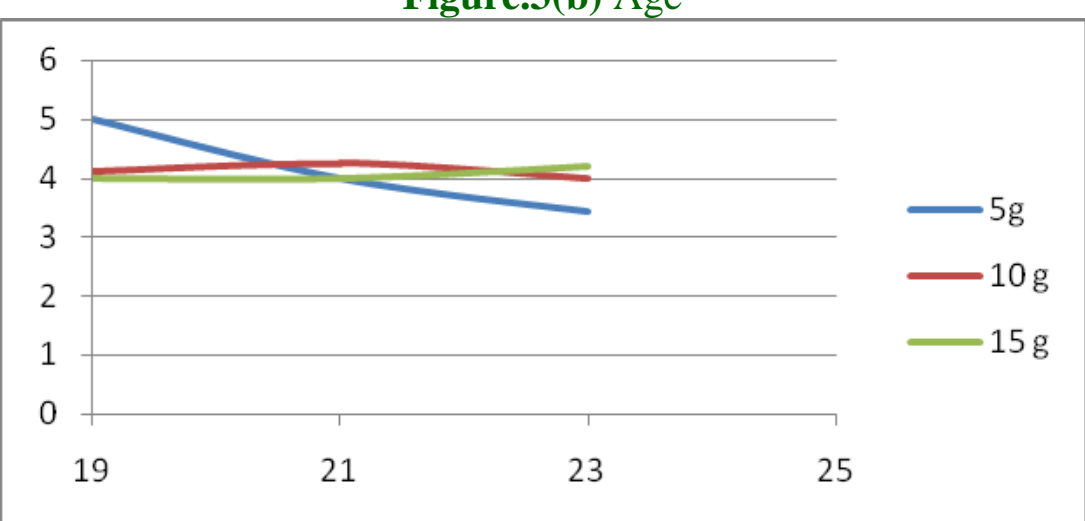

Age in years

Figure.3(c) Weight

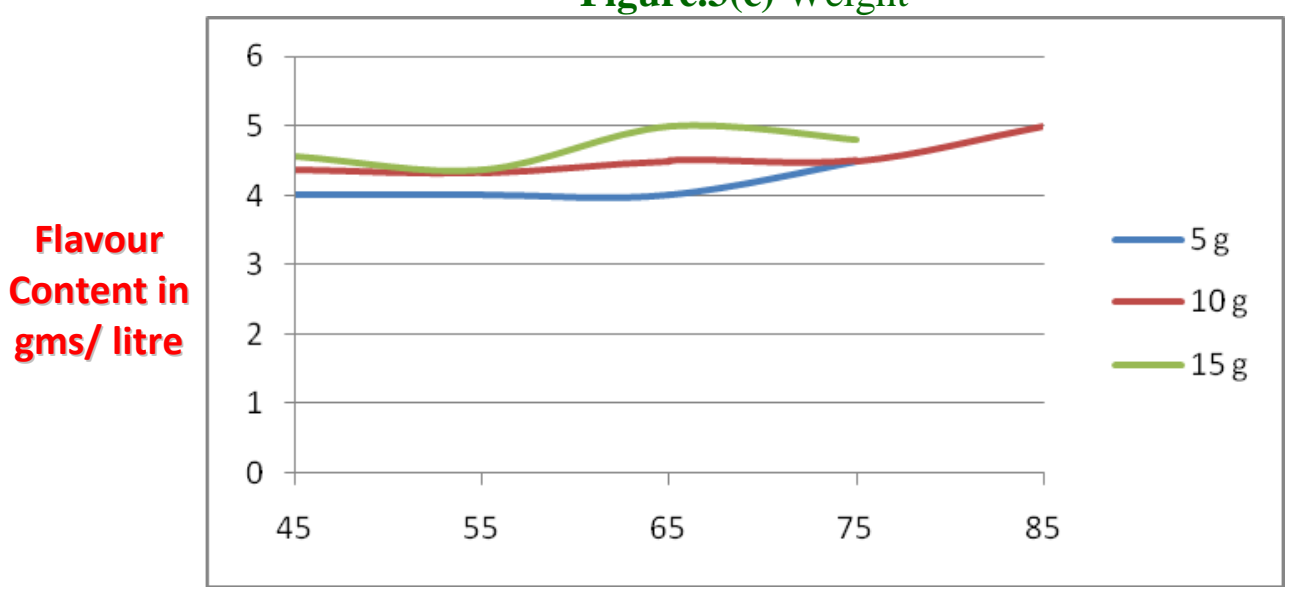

Weight in kgs
In terms of age for all the 3 different types of herbal flavoured milks - it was found that for lower concentrations with the increase in age the flavour Content in gms/litre also increased and for higher concentrations with the increase in age the flavour Content in gms/litre initially increased and then gradually decreased.

In terms of weight analysis with the increase in weight of the population - it was found that the flavour content increased for low concentration samples and decreased for high concentration samples in case of lemongrass.

In the case of Tulsi it was found that with the increase in weight of the population the flavour content showed a crest and wave pattern for higher concentrations and for lower concentration there was an initial increase and then it became stagnant.

In case of Fennel - an unusual thing was noticed that for $5 \mathrm{~g}$ and $10 \mathrm{~g}$ concentrations the flavour Content in gms/litre remained constant between $45-78$ gms. For $15 \mathrm{~g}$ concentration the flavour content decreased initially and then showed an increase and then decreased.

\section{References}

Schiano A.N., Drake M. A. 2017 A 100 year old Review: Sensory analysis of Milk. 
Journal of Dairy Science 100 (12), 9966-9986, 2017

Ozer and Kirmaci H. A. 2010. Functional milks and Dairy Beverages. Intl. Journal of Dairy Technology 63(1), 1-15, 2010.

Sawale, P. D., Singh, R. R. B., and Arora, S. (2015). Stability and quality of herb (Pueraria tuberosa)-milk model system. Journal of food science and technology, 52(2), 1089-1095.

Mazid, M., Khan, T. A., and Mohammad, F. (2012). Medicinal plants of rural India: a review of use by Indian folks. Indo Global journal of pharmaceutical sciences, 2(3), 286-304.

Kumar, A., Rahal, A., Chakraborty, S., Tiwari, R., Latheef, S. K., and Dhama, K. (2013). Ocimum sanctum (Tulsi): a miracle herb and boon to medical science-A Review. Int $\mathbf{J}$ Agron Plant Prod, 4(7), 1580-9.

Veena N, Arora S, Singh R R B, Katara A, Rastogi S and Rawat A K S, 2015. Effect of Asparagus racemosus (Shatavari) extract on physicochemical and functional properties of milk and its interaction with milk proteins. J Food Sci. Tech, 52: 1176-1181.

Sawale, P. D., Singh, R. R. B., and Arora, S. (2015). Stability and quality of herb (Pueraria tuberosa)-milk model system.
Journal of food science and technology, 52(2), 1089-1095. (www.amul.com/ products/Amul-MemoryMilk)

Palthur, S., Anuradha, C. M., and Devanna, N. (2014). Development and evaluation of ginger flavored herbal milk. Res J Agric Env Sci, 1, 54-59.

Chourasia, S. (2010). Development of novel sterilized herbal flavoured milk (Doctoral dissertation, Indira Gandhi Krishi Vishwavidyalaya, Raipur).

Shah G, Shri R, Mann A. S, 2011 Scientific basis for the therapeutic use of Cymbopogon citratus, stapf (Lemongrass). J Adv. Pharma. Tech. and Res, 2(1), 3, 2011.

Kadian R, Parle M, 2012 Therapeutic potential and phytopharmacology of Tulsi. Intl. J. Pharma. and Life Sciences 3 (7), 2012.

Fennel Akbar S, 2018 A Common Spice with Unique Medicinal Properties. Ann Complement Altern. Med. 2018; 1(1) 1001.

Tuorila H, 2015 From Sensory Evaluation to sensory and consumer research of food: An autobiographical perspective. Food quality and preference 40,255-262, 2015.

\section{How to cite this article:}

Mogla Achal Maharaj Kishore, D.K. Chaturvedi and Dantu, P.K. 2020. Herbal Flavoured Milk and Sensory Evaluation. Int.J.Curr.Microbiol.App.Sci. 9(05): 1861-1870.

doi: https://doi.org/10.20546/ijcmas.2020.905.211 